\title{
MicroRNAs and Breast Cancer
}

\author{
Victoria J. Findlay* \\ Department of Pathology and Laboratory Medicine, College of Medicine, Medical University of South Carolina, \\ Charleston, South Carolina 29425, USA
}

\begin{abstract}
MicroRNAs are a class of small non-coding RNAs that are involved in the negative regulation of gene expression primarily through binding to the 3'untranslated region of their target mRNA. MicroRNAs have multiple mRNA targets, each of which can be regulated by multiple microRNAs making this a complex regulatory network. The identification of their importance in different types of cancer and validation of their role in many processes related to cancer progression led to their description as a novel class of oncogenes (or 'oncomirs') and tumor suppressors. As a result, a massive influx of related research articles has emerged. Understanding the role of microRNAs in normal breast and cancer development and progression is critical to fully comprehend this disease. Many insights have been gained to date and this review highlights those with well established roles in breast cancer, as well as providing a comprehensive depiction of the most recent research articles in the field of microRNAs and breast cancer.
\end{abstract}

\section{MICRORNAS: AN INTRODUCTION}

MicroRNAs (miRNAs) are endogenous 19-25 nucleotide RNAs that have recently emerged as a novel class of small, evolutionarily conserved gene regulatory molecules involved in many critical developmental and cellular functions [1]. miRNAs base-pair with target mRNA sequences primarily in their 3' untranslated region (3'UTR). Through specific base pairing, miRNAs induce mRNA degradation, translational repression, or both depending upon the complementarity of the miRNA to its mRNA target. Each miRNA can target numerous (100-1000) mRNAs, often in combination with other miRNAs, therefore controlling complex regulatory networks. It is estimated that there are $\sim 900$ miRNAs in mammalian cells, and that at least $30 \%$ of all genes are regulated by miRNAs $[2,3]$. Over 10,000 identified mature miRNAs exist in species ranging from plants to humans, suggesting that miRNAs are ancient players in gene regulation [4]. Their existence and conservation throughout species supports the concept that they perform critical functions in gene regulation [4]. Indeed, the conserved evolution of both miRNAs and transcription factors highlights their importance in and the complexity of gene regulation [5].

Although, the primary role for miRNAs is through base pairing in the 3'UTR of genes as described above, there is compelling evidence that miRNAs may also bind to regions in the coding sequence of genes (for a review [6]). In addition, there is evidence to suggest that miRNAs may lead to the activation of certain genes through binding to sequences in the 5'UTR of genes [7]. Cleary, the complexity of miRNA-mediated regulation is still not yet fully realized and we should anticipate many advances in this field in the not too distant future.

*Address correspondence to this author at the Department of Pathology \& Laboratory Medicine, Hollings Cancer Center, 86 Jonathan Lucas Street, Medical University of South Carolina, Charleston, SC 29425, USA; Tel: 843-792-7889; Fax: 843-792-3940; E-mail: findlay@musc.edu
What makes miRNAs particularly important is their involvement in most, if not all, fundamental biological processes [8-10]. Mounting evidence indicates that miRNAs may also play a significant role in cellular transformation and carcinogenesis acting either as oncogenes or tumor suppressors [11-16]. Furthermore, specific miRNA signatures have been identified for both solid cancers and hematologic malignancies [17-20]. Intriguingly, mounting evidence suggest that the power of miRNAs lies in the ability to distinguish specific cancer subtypes based on their miRNA profile, including, and of direct relevance to the studies described herein, breast cancer [17, 21]. Nonetheless, the identification and validation of specific targets has been limited.

\section{MICRORNA BIOGENESIS}

There have been reports of dysregulation of the biogenesis machinery in breast cancer. Transcriptional regulation of miRNAs is still not well understood; however, it is known that miRNAs can reside within genes (intronic) or between genes (intergenic) and studies have shown that they can be transcribed from both host and independent promoters [22]. The biogenesis of miRNAs begins with transcription in the nucleus by RNA polymerase II or III into primary miRNA (pri-miRNA) transcripts [23]. The pri-miRNAs are then cleaved by the microprocessor complex Drosha-DGCR8 (Pasha) in the nucleus to a $\sim 70$ nucleotide precursor or premiRNA. This precursor hairpin is then exported into the cytoplasm by Exportin 5 in complex with Ran-GTP [24]. In the cytoplasm the RNase III Dicer cleaves off the loop of the pre-miRNA and generates an $\sim 22$-nucleotide miRNA duplex. Following Dicer-mediated cleavage, a miRNP (miRNAcontaining ribonucleoprotein particle) complex containing Argonaute protein separates the miRNA duplex by binding the strand with the less stable hydrogen bonding at its 5'end. This strand becomes the mature, functionally active miRNA [25]. The other strand is degraded. This simple, linear view of miRNA biogenesis is sufficient for this review, but as with all processes the complexity involved is 
vast and is beyond the scope of this review and as described by Diederichs group, there are "Many roads to maturity" [26].

A recent study examined the biological and prognostic value of Dicer expression at both the RNA and protein level in breast cancer cell lines, breast cancer progression cellular models, and in two well-characterized sets of breast carcinoma samples obtained from patients with long-term followup using tissue microarrays and quantitative reverse transcription-PCR [27]. In summary, the study found that Dicer protein expression is significantly associated with hormone receptor status and cancer subtype in breast tumors (ER $\mathrm{p}=0.008$; PR $\mathrm{p}=0.019$; cancer subtype $\mathrm{p}=0.023$, luminal A $\mathrm{p}=0.0174$ ). In addition, they showed that Dicer mRNA expression appeared to have an independent prognostic impact in metastatic disease (hazard ratio $=3.36, p=0.0032$ ), suggesting that assessment of Dicer expression may facilitate prediction of distant metastases for patients suffering from breast cancer. Although studies on Dicer manipulation in breast cancer are limited, one study has shown that knockdown of Dicer by siRNA led to a significant G1 arrest and increased sensitivity to the DNA damaging agent, cisplatin, in MCF7 breast cancer cells, suggesting that overexpression of Dicer may be pro-tumorigenic [28].

\section{MICRORNAS IN BREAST CANCER}

The link between miRNAs and cancer attracted many researchers to this new and exciting field of research. The outcome resulted in a plethora of studies linking miRNA expression profiles with specific types of cancer, tumor subtypes, and even metastatic signatures from expression profiling and microarrays. In addition, functional studies have identified specific miRNAs as tumor suppressors and oncogenes and have linked their expression in breast cancer with the translational regulation of direct mRNA targets. The table below lists those miRNAs identified as playing a role in breast cancer (Table 1); however, this review will highlight some of the more recent advances in miRNAs and breast cancer.

\section{miR-21}

\section{Upstream Regulation}

Since its initial discovery, miR-21 has become one of the most studied miRNAs in various fields of biology (for a detailed review see [51]). More recently, expression of miR21 has been linked with the hyaluronan (HA)-induced interaction with CD44 and protein kinase $\mathrm{C}(\mathrm{PKC})$ epsilon in breast tumor cells [52]. HA binding to CD44 promotes PKC epsilon activation, which in turn increases the phosphorylation of the stem cell marker Nanog resulting in translocation from the cytosol to the nucleus and association with Drosha and p68 (RNA helicase). This process leads to the production of miR-21 and the subsequent decrease in PDCD4, a tumor suppressor protein and direct target of miR21 . The authors show that these events contribute to the upregulation of IAPs (inhibitors of apoptosis proteins) and MDR1 (multidrug resistance protein), resulting in antiapoptosis and chemotherapy resistance.

Estradiol (E2) was shown to inhibit miR-21 expression in MCF7 breast cancer cells [53]. They also showed that the E2-mediated decrease correlated with increased protein expression of endogenous miR-21 targets PDCD4, PTEN and Bcl-2. Conversely, a later study showed that miR-21 was induced in response to E2 along with 21 other miRNAs. Notably, 7 other miRNAs were reduced in the E2 treated MCF7 breast cancer cells [54]. The experimental differences (time in serum-free, charcoal stripped media and concentration and time of E2 treatment) may account for these effects. A recent study showed miR-21 to be correlated with HER2/neu up-regulation and functionally involved in HER2/ neu-induced cell invasion via the MAPK (ERK1/2) pathway

Table 1. MicroRNAs and their Target Genes in Breast Cancer

\begin{tabular}{|c|c|c|c|}
\hline $\operatorname{miR}-21$ & Over-expressed, oncogenic & BCL2, TPM1, PDCD4, PTEN & [29-32] \\
\hline $\operatorname{miR}-27 \mathrm{a}$ & Oncogenic (breast cancer cells) & ZBTB10 & {$[34]$} \\
\hline miR-206 & Over-expressed & ER alpha & {$[35,36]$} \\
\hline $\operatorname{miR}-125 \mathrm{a} \& \mathrm{~b}$ & Down-regulated, tumor suppressor & ERBB2, ERBB3 & {$[38,39]$} \\
\hline miR-200 family & Down-regulated, metastasis suppressor & ZEB1, ZEB2 & {$[40,41]$} \\
\hline miR-205 & Down-regulated, tumor suppressor & ERBB3, VEGF-A, ZEB1, ZEB2 & {$[40-43]$} \\
\hline miR-146a \& b & Metastasis suppressor & EGFR & {$[44]$} \\
\hline $\operatorname{miR}-145$ & Down-regulated & RTKN, ER alpha & {$[48,49]$} \\
\hline miR-155 & Oncogenic & RhoA & {$[50]$} \\
\hline
\end{tabular}


upon stimulation of HER2/neu signaling in breast cancer cells [55]. Conversely, miR-21 has been shown to be repressed by BMP-6 (bone morphogenetic protein -6) through the E2-box and AP-1-binding sites within the promoter of miR-21 [56]. This study further showed using site-directed mutation and ChIP that miR-21 was activated by deltaEF1 by binding to the E2 box on the miR-21 promoter and furthermore that TPA triggered miR-21 activity through the AP-1 binding site.

\section{Downstream Regulation}

Direct targets of miR-21 were identified using a quantitative proteomic approach in MCF7 breast cancer cells [57]. This group observed an increase in the abundance of 58 proteins when miR-21 was inhibited. Validation of 12 of these candidate targets in luciferase assays showed that 6 of them were likely direct targets of miR-21, one of which included the known miR-21 target gene PCDC4. Of the 5 potentially novel targets identified in this screen, only $2 / 5$ contained the 'required' 7 mer seed, therefore are unlikely to be predicted by the bioinformatic databases available for target identification. This study also highlighted the importance of proteomic approaches of miRNA target identification as many of the targets identified in this study were not affected at the mRNA level.

\section{Clinical Significance}

Three studies recently examined the potential clinical significance of miR-21 expression in breast cancer. One study showed that miR-21 expression was associated with lymph node positivity $(\mathrm{p}=0.01)$, higher proliferation index $(\mathrm{Ki} 67>10 \% ; \mathrm{p}=0.03)$ and advanced TNM clinical stage $(\mathrm{p}=0.021)$ using matched non-tumor and tumor tissues of 40 invasive ductal carcinomas of the breast. This study also reported a negative correlation with PTEN expression $(\mathrm{p}=0.013)$, a known downstream target of miR-21, in the same tissues [58]. The second study showed that high miR21 expression was associated with features of aggressive disease, including high tumor grade, negative hormone receptor status, and ductal carcinoma, as well as a positive correlation with TGF-beta1 [59]. Although no association was found between patient survival and miR-21 expression among all patients, high miR-21 was associated with poor disease-free survival in early stage patients $(\mathrm{HR}=2.08,95 \%$ CI: 1.08-4.00) despite no value for prognosis. The third study performed global expression profiling of miRNAs in primary breast cancer (BC) and normal adjacent tumor tissues (NATs) and its potential relevance to clinicpathological characteristics and patient survival [31]. Among the $113 \mathrm{BC}$ cases, this study found high level expression of miR-21 was significantly correlated with advanced clinical stage $(p=0.006$, Fisher's exact text), lymph node metastasis $(p=0.007$, Fisher's exact text), and shortened survival of the patients $(\mathrm{HR}=5.476, \mathrm{p}<0.001)$. In addition, multivariate Cox regression analysis revealed this prognostic impact $(\mathrm{HR}=4.133, \mathrm{p}=0.001)$ to be independent of disease stage $(\mathrm{HR}=2.226, \mathrm{p}=0.013)$ and histological grade $(\mathrm{HR}=3.681$, $\mathrm{p}=0.033$ ).

\section{miR-193b}

Of interest, miR-193b was initially identified and further validated as a negative regulator of the estrogen receptor- alpha (ER alpha), in a high-throughput screen [46]. Recently identified miR-193b was shown to be differentially expressed between the MDA-MB-231 breast cancer cell line and its highly metastatic variant, the highly metastatic variant showing reduced expression of miR-193b [47]. Further analysis revealed that $\mathrm{miR}-193 \mathrm{~b}$ repressed $\mathrm{uPA}$ protein expression and inhibited cell invasion through a binding site present within its 3'UTR. Furthermore, this study showed that miR-193b significantly inhibited the growth and dissemination of xenograft tumors in an immunodeficient mouse model and that miR-193b was a negative regulator of uPA in primary breast tumors.

\section{miR-206}

miR-206 was initially identified as a negative regulator of ER alpha mRNA and protein expression in breast cancer cell lines through two specific target sites within its 3'UTR and that miR-206 and ER alpha repress each other's expression in MCF-7 cells in a double-negative feedback loop [35]. Another group further showed that miR-206 expression is decreased in ER alpha-positive human breast cancer tissues and that its expression is inversely correlated with ER alpha, but not ER beta mRNA expression [36]. More recently, a study identified the co-activator proteins steroid receptor co-activator (SRC)-1 and SRC-3, and the transcription factor GATA-3, all of which contribute to estrogenic signaling and a Luminal-A phenotype as novel downstream targets of miR-206 [60]. Significantly, they showed that over-expression of miR-206 repressed estrogenmediated responses in MCF-7 cells, even in the presence of ER alpha encoded by an mRNA lacking a 3'UTR, suggesting miR-206 affects estrogen signaling by targeting mRNAs encoding ER alpha-associated co-regulatory proteins.

\section{miR-125b}

Similar to the identification of other miRNAs, miR-125b was initially identified in a miRNA profiling study to define miRNAs that were aberrantly expressed between normal tissue and breast cancer [38]. In this study, miR-125b levels were found to be down-regulated in breast cancer when compared to normal, however no correlation was found with invasive breast cancer pathological features including estrogen receptor (ER), progesterone receptor $(\mathrm{PR})$ and $\mathrm{p} 53$ status, tumor stage (pT), positive lymph nodes $(\mathrm{pN})$ and low/ high proliferation index (PI). Since then, multiple studies have reported down-regulation of $\mathrm{miR}-125 \mathrm{~b}$ in breast cancer, particularly in ER positive tumors and suppression of ERBB2 and ERBB3 expression and function [39, 61-63]. Human vitamin D3 hydroxylase (CYP24), a candidate oncogene [64], was recently identified as a direct target of miR-125b [65]. Modulation of miR-125b levels resulted in altered CYP24 protein levels with no change in mRNA levels. Significantly, immunohistochemical analysis showed an inverse correlation between CYP24 protein levels and miR-125b levels in breast cancer/normal tissues, suggesting post-transcriptional regulation of CYP24 by miR-125b as a possible mechanism for high CYP24 protein expression in cancer tissues. More recently, a study identified a single nucleotide polymorphism (SNP) within a miR-125b binding site in the 3'UTR of the bone morphogenic receptor type $1 \mathrm{~B}$ (BMPR1B) encoding a transmembrane serine/threonine 
kinase [66]. They show that miR-125b negatively regulates $\mathrm{BMPR} 1 \mathrm{~B}$ and that $\mathrm{C} / \mathrm{T}$ allelic variation within the target site disrupts this regulation. The presence of the $\mathrm{T}$ allele leads to loss of miR-125b regulation, increased BMPR1B expression, and ultimately elevated risk of breast cancer disease. This study is the first to suggest that genomic variation within miRNA target sites may be important sources for genetic differences in cancer risk.

\section{miR-205}

The aberrant expression of miR-205 has been demonstrated for multiple cancers [67-74]. Focusing specifically on breast, miR-205 has been shown to be a tumor suppressor; significantly, under-expressed in breast tumor compared to matched normal breast tissue [42, 43]. Functionally, ectopic expression of miR-205 inhibits cell proliferation, invasion and anchorage-independent growth in breast cancer cell lines through direct targeting of ERBB3 and VEGF-A [43]. Furthermore, together with members of the miR-200 family, miR-205 has been shown to regulate epithelial-mesenchymal transition (EMT) by targeting the E-cadherin transcriptional repressors $\mathrm{ZEB} 1$ and $\mathrm{ZEB} 2$, suggesting a potential role for miR-205 in cancer metastasis [40, 41]. The expression pattern of miR-205 was identified to be restricted to the myoepithelial/basal cell compartment of normal mammary ducts and lobules, whereas the expression was greatly reduced or eliminated in matching tumor specimens [75].

\section{miR-204 and -510}

Two miRNAs, miR-204 and miR-510, were recently identified as potential 'oncomirs' in breast cancer [45]. This study showed that the levels of miR-204 and miR-510 are elevated in human breast tumor samples when compared to matched non-tumor. In addition, this study shows that an increase in migration, invasion and colony formation occurred when miR-204 or miR-510 were over-expressed in the non-invasive breast cancer cell line MCF7. The ETS transcription factor and putative tumor suppressor, PDEF (prostate-derived ETS factor) was identified as a direct target for miR-204 and miR-510 with distinct and functional binding sites for each present in the 3'UTR.

\section{Other miRNAs of Interest}

Other recent studies of interest include the miRNA link made between breast cancer stem cells (BCSC) and normal stem cells. Specifically, 37 miRNAs were found that were differentially expressed between BCSCs and non-tumorigenic cancer cells. miR-200c modulated the expression of BMI1, a known regulator of stem cell self-renewal, and inhibited the clonal expansion of breast cancer cells in vitro [76]. Furthermore, this study showed that miR-200c suppressed the ability of normal mammary stem cells to form mammary ducts and tumor formation driven by BCSCs in vivo.

The breast cancer metastasis suppressor 1 (BRMS1) protein is able to suppress metastasis without affecting tumorigenesis. BRMS1 was shown to exert some of its antimetastatic effects by regulating miRNA expression [77]. Specifically, the down-regulation of metastasis-promoting miRNAs $-10 b,-373$ and $-520 c$, and the up-regulation of metastasis suppressing miRNAs $-146 a,-146 b$ and -335 . In a separate study, miR-31 was identified as a metastasis suppressor [78]. In this study, inhibition of miR-31 allowed normally non-aggressiveness breast cancer cells to metastasize in vivo. They demonstrated that miR-31 can regulate multiple steps in the metastatic cascade independent of primary tumor development.

\section{MICRORNAS IN NORMAL BREAST DEVELOP- MENT}

It is widely accepted that understanding the regulation of developmental processes results in a better understanding of how these pathways may become dysregulated and ultimately result in cancer. However, the role of miRNAs in normal breast development has not been well studied and much work is needed to understand their role in this highly complex process. Studies to date have shown that there is a human 'breast'-specific signature composed of 23 miRNA based on microarray data [79]. However, only 161 human and 84 mouse miRNA were present on this array and therefore a true representation of the miRNome remains to be established. In addition, RNA samples analyzed were from 18 adult and 2 fetal normal human tissues and therefore were not adequate to assess miRNA expression patterns during the complex and distinct stages of normal mammary development. More recently, a preliminary study was performed to analyze the expression pattern of 22 miRNAs in mouse mammary gland from various development stages [80]. Taken together with the fact that of these 22 miRNAs, over half $(13 / 22)$ were not detected in the mammary gland, this is not a comprehensive enough study to assess the role of miRNAs in normal mammary gland development. Subsequent analyses from this group has performed a more complete analysis of miRNA expression in normal mammary gland development using a small RNA cloning method [81]. Using this technique, they were able to identify 3 known and 33 new miRNAs, some of which were differentially expressed during different stages of mammary gland development. Indeed, another study was performed using microarray and qRT-PCR to analyze the miRNA expression changes along the murine mammary cycle during pregnancy, particularly on transition from pregnancy to lactation [82]. This study illustrates that a miRNA expression pattern exists for each developmental stage of the mammary gland. Downregulation of some miRNAs, such as miR-138 and miR-431, are observed in virgin compared to involution, whereas other miRNAs, such as miR-133 and miR-133a-133b, are up-regulated during pregnancy and lactation. These initial studies highlight the importance of miRNAs in normal developmental processes in the mammary gland and that future studies identifying direct targets and functional consequences of these differentially expressed miRNAs are essential to fully understand the normal developmental processes in the breast.

\section{MICRORNA FUTURE DEVELOPMENTS}

\section{Diagnostic/Prognostic/Therapeutic}

Specific miRNA signatures have been identified for both solid cancers and hematologic malignancies, and mounting 
evidence suggest that the power of miRNAs lies in their ability to distinguish specific cancer subtypes based on their miRNA profile, including, and of direct relevance to this review, breast cancer. Patient stratification (i.e., selecting patients likely to respond to treatment and thus significantly improve response rates and potential patient survival) is an achievable objective if there is adequate knowledge of drug targets and their biology. Increasing evidence suggests that miRNAs regulate many of the biological processes associated with human disease, including cancer.

One of the major challenges in ASO development has been the instability of ASOs in serum. Modified synthetic antisense miRNA oligoribonucleotides (AMO) are useful tools in specifically inhibiting individual miRNAs, and are a proven resource in helping to unravel the function of miRNAs and their targets. Similar to antisense-based oligonucleotides (ASO), AMOs may contribute to the prioritization of pharmaceutical targets and have the potential to eventually progress into a new class of therapeutic agents. Another more recent advance in antisense technology is the emergence of peptide nucleic acids (PNAs) [83]. PNAs are artificial oligonucleotides constructed on a peptide-like backbone, that have a stronger affinity and greater specificity to DNA or RNA than natural nucleic acids and are resistant to nucleases, which is an essential characteristic for a miRNA inhibitor that will be exposed to serum and other cellular nucleases. PNA-based ASOs were also shown to be more effective miRNA inhibitors than other DNA-based ASOs, do not show non-specific cytotoxicity at concentrations up to $1000 \mathrm{nM}$ and were shown to persist for 9 days in vitro [83]. Although PNA-ASO technology is moving in the right direction, these ASOs remain to be tested in an in vivo environment. The challenges for any in vivo inhibitors will be to control off-target effects, to design approaches for achieving a long duration of effectiveness, and to carefully titrate the expression level of a given miRNA so that it affects a selective, disease related endpoint.

\section{ABBREVIATIONS}

$\begin{array}{ll}\text { miRNA } & =\text { MicroRNA } \\ \text { 3'UTR } & =3^{\prime} \text { Untranslated region } \\ \text { pri-miRNA } & =\text { Primary miRNA } \\ \text { miRNP } & =\text { miRNA-containing ribonucleoprotein } \\ \text { ER } & =\text { Estrogen receptor } \\ \text { PR } & =\text { Progesterone receptor } \\ \text { PKC } & =\text { Protein kinase C } \\ \text { E2 } & =\text { Estradiol } \\ \text { HA } & =\text { Hyaluronan } \\ \text { IAPs } & =\text { Inhibitors of apoptosis proteins } \\ \text { MDR1 } & =\text { Multidrug resistance protein } \\ \text { BC } & =\text { Breast cancer } \\ \text { NATs } & =\text { Tormal adjacent tumor tissues } \\ \text { pT } & \end{array}$

$\begin{array}{ll}\mathrm{pN} & =\text { Positive lymph nodes } \\ \mathrm{PI} & =\text { Proliferation index } \\ \mathrm{CYP} 24 & =\text { Human vitamin D3 hydroxylase } \\ \mathrm{SNP} & =\text { Single nucleotide polymorphism } \\ \mathrm{BMPR} 1 \mathrm{~B} & =\text { Bone morphogenic receptor type 1B } \\ \mathrm{EMT} & =\text { Epithelial-mesenchymal transition } \\ \mathrm{PDEF} & =\text { Prostate-derived ETS factor } \\ \mathrm{BCSC} & =\text { Breast cancer stem cells } \\ \mathrm{BRMS1} & =\text { Breast cancer metastasis suppressor 1 } \\ \mathrm{AMO} & =\text { Antisense miRNA oligoribonucleotides } \\ \text { ASO } & =\text { Antisense-based oligonucleotides }\end{array}$

\section{REFERENCES}

[1] Wiemer EA. The role of microRNAs in cancer: no small matter. Eur J Cancer 2007; 43: 1529-44.

[2] Rajewsky N. microRNA target predictions in animals. Nat Genet 2006; 38 (Suppl. S): 8-13.

[3] Shilo S, Roy S, Khanna S, Sen CK. MicroRNA in cutaneous wound healing: a new paradigm. DNA Cell Biol 2007; 26: 227-37.

[4] Wang Y, Stricker HM, Gou D, Liu L. MicroRNA: past and present. Front Biosci 2007; 12: 2316-29.

[5] Chen K, Rajewsky N. The evolution of gene regulation by transcription factors and microRNAs. Nature Rev 2007; 8: 93-103.

[6] Rigoutsos I. New tricks for animal microRNAS: targeting of amino acid coding regions at conserved and nonconserved sites. Cancer Res 2009; 69: 3245-8.

[7] Orom UA, Nielsen FC, Lund AH. MicroRNA-10a binds the 5'UTR of ribosomal protein mRNAs and enhances their translation. Mol Cell 2008; 30: 460-71.

[8] Hornstein E, Mansfield JH, Yekta S, et al. The microRNA miR196 acts upstream of Hoxb8 and Shh in limb development. Nature 2005; 438: 671-4.

[9] Li Y, Wang F, Lee JA, Gao FB. MicroRNA-9a ensures the precise specification of sensory organ precursors in Drosophila. Genes Dev 2006; 20: 2793-805.

[10] Neilson JR, Zheng GX, Burge CB, Sharp PA. Dynamic regulation of miRNA expression in ordered stages of cellular development. Genes Dev 2007; 21: 578-89.

[11] Calin GA, Dumitru CD, Shimizu M, et al. Frequent deletions and down-regulation of micro- RNA genes miR15 and miR16 at 13q14 in chronic lymphocytic leukemia. Proc Natl Acad Sci USA 2002; 99: 15524-9.

[12] Calin GA, Sevignani C, Dumitru CD, et al. Human microRNA genes are frequently located at fragile sites and genomic regions involved in cancers. Proc Natl Acad Sci USA 2004; 101: 29993004.

[13] Esquela-Kerscher A, Slack FJ. Oncomirs - microRNAs with a role in cancer. Nat Rev Cancer 2006; 6: 259-69.

[14] Garzon R, Fabbri M, Cimmino A, Calin GA, Croce CM. MicroRNA expression and function in cancer. Trends Mol Med 2006; $12:$ 580-7.

[15] He L, Thomson JM, Hemann MT, et al. A microRNA polycistron as a potential human oncogene. Nature 2005 ; 435: 828-33.

[16] Lu J, Getz G, Miska EA, et al. MicroRNA expression profiles classify human cancers. Nature 2005; 435: 834-8.

[17] Calin GA, Croce CM. MicroRNA signatures in human cancers. Nat Rev Cancer 2006; 6: 857-66.

[18] Calin GA, Ferracin M, Cimmino A, et al. A MicroRNA signature associated with prognosis and progression in chronic lymphocytic leukemia. N Engl J Med 2005; 353: 1793-801.

[19] Volinia S, Calin GA, Liu CG, et al. A microRNA expression signature of human solid tumors defines cancer gene targets. Proc Natl Acad Sci USA 2006; 103: 2257-61.

[20] Yanaihara N, Caplen N, Bowman E, et al. Unique microRNA molecular profiles in lung cancer diagnosis and prognosis. Cancer Cell 2006; 9: 189-98. 
[21] Blenkiron C, Goldstein LD, Thorne NP, et al. MicroRNA expression profiling of human breast cancer identifies new markers of tumor subtype. Genome Biol 2007; 8: R214.

[22] Ozsolak F, Poling LL, Wang Z, et al. Chromatin structure analyses identify miRNA promoters. Genes Dev 2008; 22: 3172-83.

[23] Lee Y, Kim M, Han J, et al. MicroRNA genes are transcribed by RNA polymerase II. EMBO J 2004; 23: 4051-60.

[24] Yi R, Qin Y, Macara IG, Cullen BR. Exportin-5 mediates the nuclear export of pre-microRNAs and short hairpin RNAs. Genes Dev 2003; 17: 3011-6.

[25] Gregory RI, Chendrimada TP, Cooch N, Shiekhattar R. Human RISC couples microRNA biogenesis and posttranscriptional gene silencing. Cell 2005; 123: 631-40.

[26] Winter J, Jung S, Keller S, Gregory RI, Diederichs S. Many roads to maturity: microRNA biogenesis pathways and their regulation. Nat Cell Biol 2009; 11: 228-34.

[27] Grelier G, Voirin N, Ay AS, et al. Prognostic value of Dicer expression in human breast cancers and association with the mesenchymal phenotype. Br J Cancer 2009; 101: 673-83.

[28] Bu Y, Lu C, Bian C, et al. Knockdown of Dicer in MCF-7 human breast carcinoma cells results in G1 arrest and increased sensitivity to cisplatin. Oncol Rep 2009; 21: 13-7.

[29] Krichevsky AM, Gabriely G. miR-21: a small multi-faceted RNA. J Cell Mol Med 2009; 13: 39-53.

[30] Bourguignon LY, Spevak CC, Wong G, Xia W, Gilad E. Hyaluronan-CD44 interaction with protein kinase $\mathrm{C}$ (epsilon) promotes oncogenic signaling by the stem cell marker Nanog and the Production of microrna-21, leading to down-regulation of the tumor suppressor protein PDCD4, anti-apoptosis, and chemotherapy resistance in breast tumor cells. J Biol Chem 2009; 284: 2653346

[31] Lu Z, Liu M, Stribinskis V, et al. MicroRNA-21 promotes cell transformation by targeting the programmed cell death 4 gene. Oncogene 2008; 27: 4373-9.

[32] Si ML, Zhu S, Wu H, Lu Z, Wu F, Mo YY. miR-21-mediated tumor growth. Oncogene 2007; 26: 2799-803.

[33] Yan LX, Huang XF, Shao Q, et al. MicroRNA miR-21 overexpression in human breast cancer is associated with advanced clinical stage, lymph node metastasis and patient poor prognosis. RNA (New York, NY) 2008; 14: 2348-60.

[34] Zhu S, Si ML, Wu H, Mo YY. MicroRNA-21 targets the tumor suppressor gene tropomyosin 1 (TPM1). J Biol Chem 2007; 282: 14328-36.

[35] Ma L, Teruya-Feldstein J, Weinberg RA. Tumour invasion and metastasis initiated by microRNA-10b in breast cancer. Nature 2007; 449: 682-8.

[36] Mertens-Talcott SU, Chintharlapalli S, Li X, Safe S. The oncogenic microRNA-27a targets genes that regulate specificity protein transcription factors and the G2-M checkpoint in MDA-MB-231 breast cancer cells. Cancer Res 2007; 67: 11001-11.

[37] Adams BD, Furneaux H, White BA. The micro-ribonucleic acid (miRNA) miR-206 targets the human estrogen receptor-alpha (ERalpha) and represses ERalpha messenger RNA and protein expression in breast cancer cell lines. Mol Endocrinol 2007; 21 : 1132-47.

[38] Kondo N, Toyama T, Sugiura H, Fujii Y, Yamashita H. miR-206 Expression is down-regulated in estrogen receptor alpha-positive human breast cancer. Cancer Res 2008; 68: 5004-8.

[39] Hossain A, Kuo MT, Saunders GF. Mir-17-5p regulates breast cancer cell proliferation by inhibiting translation of AIB1 mRNA. Mol Cell Biol 2006; 26: 8191-201.

[40] Iorio MV, Ferracin M, Liu CG, et al. MicroRNA gene expression deregulation in human breast cancer. Cancer Res 2005; 65: 706570 .

[41] Scott GK, Goga A, Bhaumik D, Berger CE, Sullivan CS, Benz CC. Coordinate suppression of ERBB2 and ERBB3 by enforced expression of micro-RNA miR-125a or miR-125b. J Biol Chem 2007; 282: 1479-86

[42] Gregory PA, Bert AG, Paterson EL, et al. The miR-200 family and miR-205 regulate epithelial to mesenchymal transition by targeting ZEB1 and SIP1. Nat Cell Biol 2008; 10: 593-601.

[43] Paterson EL, Kolesnikoff N, Gregory PA, Bert AG, Khew-Goodall Y, Goodall GJ. The microRNA-200 family regulates epithelial to mesenchymal transition. Sci World J 2008; 8: 901-4.

[44] Iorio MV, Casalini P, Piovan C, et al. microRNA-205 regulates HER3 in human breast cancer. Cancer Res 2009; 69: 2195-200.
[45] Wu H, Zhu S, Mo YY. Suppression of cell growth and invasion by miR-205 in breast cancer. Cell Res 2009; 19: 439-48.

[46] Hurst DR, Edmonds MD, Scott GK, Benz CC, Vaidya KS, Welch DR. Breast cancer metastasis suppressor 1 up-regulates miR-146, which suppresses breast cancer metastasis. Cancer Res 2009; 69: 1279-83.

[47] Findlay VJ, Turner DP, Moussa O, Watson DK. MicroRNAmediated inhibition of prostate-derived Ets factor messenger RNA translation affects prostate-derived Ets factor regulatory networks in human breast cancer. Cancer Res 2008; 68: 8499-506.

[48] Leivonen SK, Makela R, Ostling P, et al. Protein lysate microarray analysis to identify microRNAs regulating estrogen receptor signaling in breast cancer cell lines. Oncogene 2009; 28: 3926-36.

[49] Li XF, Yan PJ, Shao ZM. Downregulation of miR-193b contributes to enhance urokinase-type plasminogen activator (uPA) expression and tumor progression and invasion in human breast cancer. Oncogene 2009; 28: 3937-48.

[50] Wang S, Bian C, Yang Z, et al. miR-145 inhibits breast cancer cell growth through RTKN. Inter J Oncol 2009; 34: 1461-6.

[51] Spizzo R, Nicoloso MS, Lupini L, et al. miR-145 participates with TP53 in a death-promoting regulatory loop and targets estrogen receptor-alpha in human breast cancer cells. Cell Death Diff 2009; 17, 246-54

[52] Kong W, Yang H, He L, et al. MicroRNA-155 is regulated by the transforming growth factor beta/Smad pathway and contributes to epithelial cell plasticity by targeting RhoA. Mol Cell Biol 2008; 28 : 6773-84.

[53] Wickramasinghe NS, Manavalan TT, Dougherty SM, Riggs KA, Li Y, Klinge CM. Estradiol downregulates miR-21 expression and increases miR-21 target gene expression in MCF-7 breast cancer cells. Nucl Acids Res 2009; 37: 2584-95.

[54] Bhat-Nakshatri P, Wang G, Collins NR, et al. Estradiol-regulated microRNAs control estradiol response in breast cancer cells. Nucleic Acids Res 2009; 37: 4850-61.

[55] Huang TH, Wu F, Loeb GB, et al. Up-regulation of miR-21 by HER2/neu signaling promotes cell invasion. J Biol Chem 2009; 284: $18515-24$

[56] Du J, Yang S, An D, et al. BMP-6 inhibits microRNA-21 expression in breast cancer through repressing deltaEF1 and AP-1. Cell Res 2009; 19: 487-96.

[57] Yang Y, Chaerkady R, Beer MA, Mendell JT, Pandey A Identification of miR-21 targets in breast cancer cells using a quantitative proteomic approach. Proteomics 2009; 9: 1374-84.

[58] Huang GL, Zhang XH, Guo GL, et al. Clinical significance of miR-21 expression in breast cancer: SYBR-Green I-based real-time RT-PCR study of invasive ductal carcinoma. Oncol Rep 2009; 21: 673-9.

[59] Qian B, Katsaros D, Lu L, et al. High miR-21 expression in breast cancer associated with poor disease-free survival in early stage disease and high TGF-beta1. Breast Cancer Res Treat 2009; 117: $131-40$

[60] Adams BD, Cowee DM, White BA. The role of miR-206 in the epidermal growth factor (EGF) induced repression of estrogen receptor-alpha (ERalpha) signaling and a luminal phenotype in MCF-7 breast cancer cells. Mol Endocrinol 2009; 23: 1215-30.

[61] Hui AB, Shi W, Boutros PC, et al. Robust global micro-RNA profiling with formalin-fixed paraffin-embedded breast cancer tissues. Lab Invest 2009; 89: 597-606.

[62] Mattie MD, Benz CC, Bowers J, et al. Optimized high-throughput microRNA expression profiling provides novel biomarker assessment of clinical prostate and breast cancer biopsies. Mol Cancer 2006; 5: 24.

[63] Baffa R, Fassan M, Volinia S, et al. MicroRNA expression profiling of human metastatic cancers identifies cancer gene targets. J Pathol 2009; 219: 214-21.

[64] Mimori K, Tanaka Y, Yoshinaga K, et al. Clinical significance of the overexpression of the candidate oncogene CYP24 in esophageal cancer. Ann Oncol 2004; 15: 236-41.

[65] Komagata S, Nakajima M, Takagi S, Mohri T, Taniya T, Yokoi T. Human CYP24 catalyzing the inactivation of calcitriol is posttranscriptionally regulated by miR-125b. Mol Pharmacol 2009; 76: 702-9.

[66] Saetrom P, Biesinger J, Li SM, et al. A risk variant in an miR-125b binding site in BMPR1B is associated with breast cancer pathogenesis. Cancer Res 2009; 69: 7459-65. 
[67] Chung TK, Cheung TH, Huen NY, et al. Dysregulated microRNAs and their predicted targets associated with endometrioid endometrial adenocarcinoma in Hong Kong women. Int J Cancer 2009; 124: 1358-65.

[68] Feber A, Xi L, Luketich JD, et al. MicroRNA expression profiles of esophageal cancer. J Thorac Cardio Surg 2008; 135: 255-60; discussion 60.

[69] Gandellini P, Folini M, Longoni N, et al. miR-205 Exerts tumorsuppressive functions in human prostate through down-regulation of protein kinase Cepsilon. Cancer Res 2009; 69: 2287-95.

[70] Gottardo F, Liu CG, Ferracin M, et al. Micro-RNA profiling in kidney and bladder cancers. Urol Oncol 2007; 25: 387-92.

[71] Iorio MV, Visone R, Di Leva G, et al. MicroRNA signatures in human ovarian cancer. Cancer Res 2007; 67: 8699-707.

[72] Markou A, Tsaroucha EG, Kaklamanis L, Fotinou M, Georgoulias V, Lianidou ES. Prognostic value of mature microRNA-21 and microRNA-205 overexpression in non-small cell lung cancer by quantitative real-time RT-PCR. Clin Chem 2008; 54: 1696-704.

[73] Tran N, McLean T, Zhang X, et al. MicroRNA expression profiles in head and neck cancer cell lines. Biochem Biophys Res Commun 2007; 358: 12-7.

[74] Wang X, Tang S, Le SY, et al. Aberrant expression of oncogenic and tumor-suppressive microRNAs in cervical cancer is required for cancer cell growth. PLoS One 2008; 3: e2557.

[75] Sempere LF, Christensen M, Silahtaroglu A, et al. Altered MicroRNA expression confined to specific epithelial cell subpopulations in breast cancer. Cancer Res 2007; 67: 11612-20.
[76] Shimono Y, Zabala M, Cho RW, et al. Downregulation of miRNA200c links breast cancer stem cells with normal stem cells. Cell 2009; 138: 592-603.

[77] Edmonds MD, Hurst DR, Vaidya KS, Stafford LJ, Chen D, Welch DR. Breast cancer metastasis suppressor 1 coordinately regulates metastasis-associated microRNA expression. Int J Cancer 2009; 125: $1778-85$.

[78] Valastyan S, Reinhardt F, Benaich N, et al. A pleiotropically acting microRNA, miR-31, inhibits breast cancer metastasis. Cell 2009; 137: 1032-46.

[79] Liu CG, Calin GA, Meloon B, et al. An oligonucleotide microchip for genome-wide microRNA profiling in human and mouse tissues. Proc Natl Acad Sci USA 2004; 101: 9740-4.

[80] Silveri L, Tilly G, Vilotte JL, Le Provost F. MicroRNA involvement in mammary gland development and breast cancer. Reprod Nutr Dev 2006; 46: 549-56.

[81] Sdassi N, Silveri L, Laubier J, et al. Identification and characterization of new miRNAs cloned from normal mouse mammary gland. BMC Genomics 2009; 10: 149.

[82] Wang $\mathrm{C}, \mathrm{Li} \mathrm{Q}$. Identification of differentially expressed microRNAs during the development of Chinese murine mammary gland. J Genet Genomics 2007; 34: 966-73.

[83] Oh SY, Ju Y, Park H. A highly effective and long-lasting inhibition of miRNAs with PNA-based antisense oligonucleotides. Mol Cells 2009; 28(4): 341-5.

Received: October 12,2009

Revised: November 15, 2009

Accepted: November 17, 2009

(C) Victoria J. Findlay; Licensee Bentham Open.

This is an open access article licensed under the terms of the Creative Commons Attribution Non-Commercial License (http://creativecommons.org/licenses/by$\mathrm{nc} / 3.0 /$ ), which permits unrestricted, non-commercial use, distribution and reproduction in any medium, provided the work is properly cited. 